\title{
Modelling of Mass Transfer Resistances in Non-uniformly Washcoated Monolith Reactors
}

\author{
M. Walander ${ }^{1}$ (D) J. Sjöblom ${ }^{1}$ - D. Creaser ${ }^{2}$ - B. Agri ${ }^{3} \cdot$ N. Löfgren ${ }^{3} \cdot$ S. Tamm ${ }^{4}$ - J. Edvardsson ${ }^{4}$
}

Received: 17 February 2020 / Revised: 6 November 2020 / Accepted: 17 November 2020 / Published online: 26 April 2021

(C) The Author(s) 2021

\begin{abstract}
There are various methodologies to account for mass transfer within non-uniformly distributed washcoats in monolith reactors in 1D models (axially). However, 1+1D models (axially/radially) fail to capture local variations in mass transfer from different coating thicknesses or cracks. In this paper, we present a novel way to account for local material properties in a washcoated monolith reactor. The suggested method uses an existing 1+1D modelling framework and sectionalizes the washcoat into multiple tangential segments which are solved independently. Intelligent gravimetric analysis and scanning electron microscopy are used in combination to calculate local effective diffusivity as an input for each simulation. The new model is compared to the original 1+1D model using NO light-off simulations. The new model predicted increased conversion at elevated temperatures, where mass transfer limitations are present, due to the higher porosity in the corners. The simulation time for each model was similar due to the parallelizable nature of the new model.
\end{abstract}

Keywords Pore diffusion · Catalytic washcoat $\cdot$ Parallel computing $\cdot$ Sectionalizing $\cdot$ Non-uniformity

\section{Introduction}

The use of liquid fuels in the internal combustion engine unintentionally produces low but significant concentrations NO, $\mathrm{CO}$ and unburnt hydrocarbons - all with significant negative environmental and health effects [1]. In order to reduce the said emissions, legislation has placed high demands on the performance of exhaust aftertreatment systems (EATS). There have been huge efforts towards development of mathematical models of monolithic catalytic reactors [2-4], with a lot of attention on the diesel oxidation catalyst (DOC) with varying degrees of complexity $[1,2,5,6]$. Although these models differ in dimensionality and inclusion of various

M. Walander

magwal@chalmers.se

J. Sjöblom

jonas.sjoblom@chalmers.se

1 Mechanics and Maritime Sciences, Chalmers University of Technology, SE-412 96 Goteborg, Sweden

2 Chemistry and Chemical Engineering, Chalmers University of Technology, SE-412 96 Göteborg, Sweden

3 Volvo Car Corporation, SE-418 78 Göteborg, Sweden

4 Johnson Matthey, SE-421 31 Göteborg, Sweden phenomena, they all rely on the so-called single channel assumption-i.e. the reaction-diffusion process that occurs within the large number of channels in a monolith reactor can be represented by a single channel [2]. In turn, this implies that all channels have similar reactant inlet concentration, volumetric flow rate and temperature. The typical reactor model is a tanks-in-series model where at least the axial dimension is discretized.

\subsection{D Models with Intrinsic Kinetics}

In general, what differentiates these models is the inclusion or exclusion of mass transfer phenomena in the catalytic coating on the substrate. The simplest models assume that the washcoat is sufficiently thin so that the mass transport rate throughout the washcoat is very fast compared to the reaction rate itself-i.e. a low value for the Thiele modulus or the second Damköhler number $\left(D a_{I I}\right)$. For example, Groppi et al. [7] deemed the critical washcoat thickness, where internal diffusion limitations are absent, to be only $10 \mu \mathrm{m}$ for hightemperature methane combustion. On the contrary, Walter et al. [8] excluded internal mass transfer limitation for oxidation of isoprene for a washcoat thicknesses below $80 \mu \mathrm{m}$. In this study, an intentionally thick washcoat has been chosen to emphasize internal mass transfer limitations. Even though it is not realistic with such a thick washcoat for a commercial, 
high-performing DOC, the catalyst is still of commercial production type and its properties should therefore be relevant.

Since the Thiele modulus has a strong temperature dependency and the DOC operation, with its multiple different occurring reactions, spans a wide range of temperatures $[9,10]$, it is very common to include an effectiveness factor to account for internal diffusion limitations [11-14].

\subsection{D Models with Effectiveness Factor}

Gunn et al. [15] developed an analytical solution, for the diffusion-reaction problem, for hollow cylinders which then was applied for round channels with an evenly distributed washcoat. A numerical method that would allow for any arbitrary shape was developed by Papadias et al. [16] and further developed by Hayes et al. [11]. The method was based on slicing the washcoat into several segments, treating each segment as a $1 \mathrm{D}$ effectiveness factor problem and then weighing together the results in an overall effectiveness factor. Although this method allows for fast computation in a 1D framework and can account for variations in washcoat thickness, neither of the published works include variations in washcoat properties along the interface. The importance on local features, such as cracks and holes, was emphasized by Kočí et al. [17]. Their CFD models, based on a 3D reconstruction of X-ray tomography images of the washcoat, showed that the presence of cracks in the coating - corresponding to $20 \%$ of the total coating volume - resulted in $41 \%$ higher local diffusivity than if cracks were absent.

\subsection{1+1D Models with Effective Diffusivity}

Another group of models not only discretizes the monolith channel in axial direction but also radially, i.e. with increased washcoat depth. Then, a mass transfer coefficient is developed through an effective diffusivity coefficient. Just like the 1D models using an effectiveness factor, the 1+1D mode can capture internal diffusion limitations-however, to the best of our knowledge, all of these axially and radially resolved models assume the washcoat to be a flat slab with uniform properties [5, 18-22]. Hence, they fail to capture differences in diffusion resistance that arise from tangential washcoat maldistributions - which could vary as much as $10 \mu \mathrm{m}$ along the side to about $150 \mu \mathrm{m}$ in the corners of the channel [23]. Furthermore, since the washcoat is only resolved in axial and radial direction, these models do not allow for local variations in washcoat properties along the coating perimeter.

\subsection{Other Relevant Models}

Mladenov et al. [13] presented a thorough numerical investigation of non-uniform washcoated monoliths, along with various channel geometries, using models of varying complexity - from simple 1D models with effectiveness factors to complete 2D and 3D CFD models coupled with multidimensional reaction-diffusion models. They concluded that for moderate-temperature NO oxidation over Pt/Alumina, internal diffusion presents the largest mass transfer limitation and that the models with reaction-diffusion models gave the best agreement with experimental data while simpler models for the gas phase sufficed for explaining the external mass transfer. The investigations in non-uniform washcoat distribution showed that the conversion was the highest in the corner region and that effect declined with more rounded corners. While the results are very relevant for this study, the authors still assume that the washcoat has uniform properties. Another relevant modelling approach is the overall mass transfer concept by Balakotaiah et al. [24, 25]. While these generic 1D models can allow an axially resolved mass transfer coefficient for any arbitrary washcoat and channel shape, which can be extended to multilayer catalysts, they cannot include local phenomena such as cracks.

In this paper, we present a novel modelling framework; combining the 1+1D DOC model developed by Lundberg et al. $[18,19]$ with a sectionalizing method similar to Papadias et al. [16] — in order to allow for an arbitrary washcoat geometry with local washcoat features such as cracks. Intelligent gravimetric analysis (IGA) and scanning electron microscopy (SEM) are used to calculate local effective diffusivities. Finally, the new model is compared to the original $1+1 \mathrm{D}$ model with regard to output and simulation time.

\section{Modelling and Experiments}

This section includes a description of the original 1+1D reactor model, the new framework (hereafter referred to as the parallel model) along with the additional experimental input that is required.

\subsection{1+1D Model}

In this section, the main features of the $1+1 \mathrm{D}$ reactor model are presented; for more details, please refer to the works of Lundberg et al. [18, 19]. Because of the small experimental reactor length $(\sim 1 \mathrm{in}$.) and low reactant concentration, it is likely that the reactor is isothermal; hence, only the mass transfer features of the model is presented here (although heat transfer in axial and radial direction are included). The discretization scheme of the model can be seen in Fig. 1.

\subsubsection{Mass Balances}

The original model is a $1+1 \mathrm{D}(1 \mathrm{D} / 2 \mathrm{D}$ gas/solid phase) tanksin-series model, employing film theory to model mass and heat transfer between the gas and solid phase. Axial diffusions 


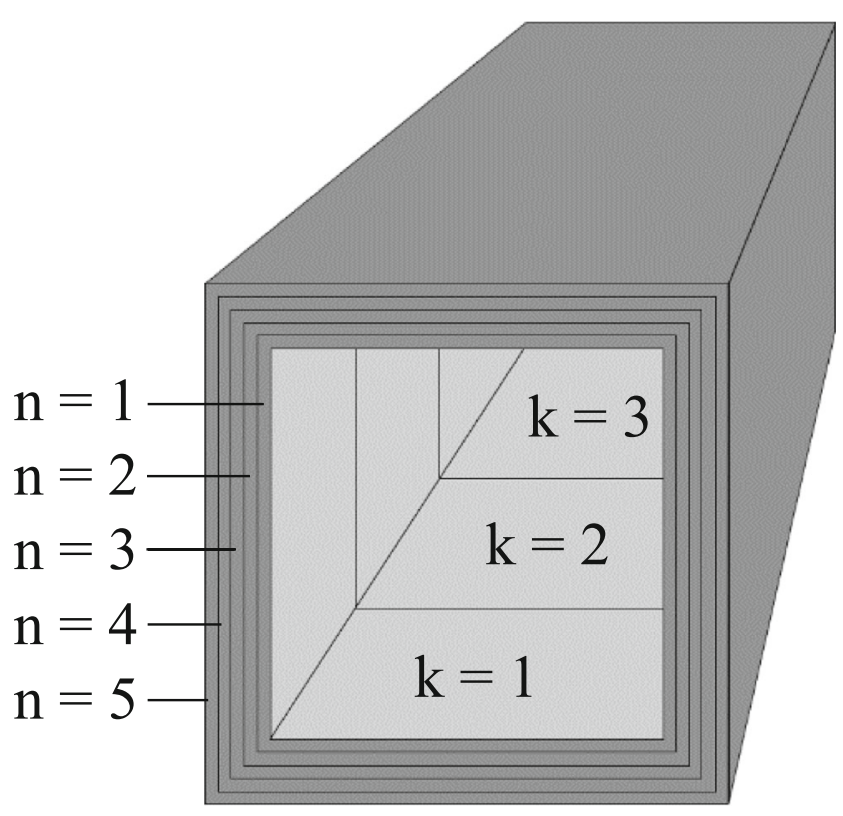

Fig. 1 Illustration of tanks-in-series scheme for the original 1+1D model for $k=3$ tanks, $n=5$ layers

in the gas and solid phase are neglected. The quasi-steadystate gas phase mass balance is given by:

$$
\begin{aligned}
0 & =\left(V_{k, n} \frac{d c_{i, k, 0}}{d t}\right) \\
& =F_{t o t}\left(y_{i,[k-1], 0}-y_{i, k, 0}\right)-\Gamma_{i, k, 0}\left(c_{i, k, 0}-c_{i, k, 1}\right)
\end{aligned}
$$

and the washcoat mass balance is:

$$
\begin{gathered}
0=\left(V_{k, n} \varepsilon \frac{d c_{i, k, n}}{d t}\right)= \\
=\Gamma_{i, k,[n-1]}\left(c_{i, k,[n-1]}-c_{i, k, n}\right)-\Gamma_{i, k, n}\left(c_{i, k, n}-c_{i, k,[n+1]}\right)+\sum_{j} v_{i, j} r_{j, k, n} m_{k, n}
\end{gathered}
$$

$\Gamma_{i, k, n}$ is the mass transfer coefficient for species $i, \operatorname{tank} k(1$ through $K$ ), and layer $n$ ( 0 for gas phase, 1 through $N$ for solid phase) given for the first layer:

$$
\Gamma_{i, k, 0}=\frac{A_{k}}{\frac{1}{k c_{i, k, 0}}+\frac{0.5 \Delta \mathrm{x}_{1}}{D_{\text {eff }, i, k}}}
$$

and for layers 2 through $(K-1)$ :

$$
\Gamma_{i, k, n}=\frac{D e f f}{0.5 \Delta x_{n}+0.5 \Delta x_{[n+1]}}
$$

and for the last layer, assuming no flux through the substrate:

$$
\Gamma_{i, j, N}=0
$$

The calculations for effective diffusivity are presented in Section 2.3. The relation for effective diffusivity is given in the section for diffusivity measurements below. Finally, the film theory mass transfer coefficient is given by:

$k \mathrm{c}_{i, k, 0}=\frac{S h D_{i, k, 0}}{d}$

The axially resolved Sherwood number, $S h$, is expressed using the correlation by Tronconi et al. [26]:

$S h=N u_{\infty, T}+8.827\left(1000 z^{*}\right)^{-0.545} \exp \left(-48.2 z^{*}\right)$

The asymptotic Nusselt value, $N u_{\infty, T}$ is set to 2.976 according to a square channel. This assumption is further discussed in the conclusion. $z^{*}$ is the dimensionless axial coordinate (also the inverse Graetz number, $z^{*}=1 / G z=d /[z$ $\operatorname{Re} S c])$.

\subsubsection{Detailed Kinetics}

The kinetics are also based on Lundberg et al. [18] and can be found summarized in Table 1.

Rate constants are treated with the Arrhenius equation using scaled temperatures [27]:

$k_{j, k, n}=k 0_{j, k, n} e^{-\frac{E a_{j}}{R}\left(\frac{1}{T_{k, n}}-\frac{1}{T_{r e f}}\right)}$

where $E a_{j}[\mathrm{~kJ} / \mathrm{mol}]$ is the activation energy, $k 0_{j, k, n}\left[\mathrm{~m}^{3} / \mathrm{s}\right]$ is the rate constant at the reference temperature $T_{r e f}[K]$ :

$k 0_{j, k, n}=A_{j} e^{-\left(\frac{E a_{j}}{R T_{r e f}}\right)}$

\subsubsection{Parameter Values}

The original 1+1D reactor model was tuned to kinetic data presented in [9]; noble metal dispersion was measured using CO TPD and some of the material properties were measured as presented below. The catalysts were aged in an oven $(25 \mathrm{~h}$ at $650{ }^{\circ} \mathrm{C}$ ) before performing any experiments to ensure a stable catalyst state. The same catalyst sample has undergone all experiments presented below, to avoid any batch to batch or sample to sample variations. Already at this stage, it should be mentioned that some kinetic parameter values are uncertain due to insufficient parameter tuning, so the temperature span for each of the operating regime might be slightly off. However, the results are still relevant as the parameter values are reasonable. The chosen catalyst samples in [9] had a very thick washcoat and low noble metal loading to ensure differential reactor operation with a wide temperature range where internal mass transfer was limiting to enable better parameter tuning. 
Table 1 Detailed reaction scheme for NO oxidation with parameter values

\begin{tabular}{|c|c|c|c|c|c|}
\hline \# & Mechanism & Reaction & Rate & $A_{j}$ & $E a_{J}$ \\
\hline 1 & $\mathrm{O}_{2}$ adsorption & $\mathrm{O}_{2}(\mathrm{~g})+2 * \rightarrow 2 O^{*}$ & $r_{1}=k_{1} C_{O_{2}} \theta_{V}^{2}$ & $2.49 \cdot 10^{6}$ & 21000 \\
\hline 2 & $\mathrm{O}_{2}$ desorption & $2 O^{*} \rightarrow O_{2}(g)+2 *$ & $r_{2}=k_{2} \theta_{O}^{2}$ & $2.08 \cdot 10^{7}$ & 56100 \\
\hline 3 & $\mathrm{NO}_{2}$ adsorption & $\mathrm{NO}_{2}(g)+1^{*} \rightarrow N O_{2}^{*}$ & $r_{3}=k_{3} C_{N O_{2}} \theta_{V}$ & $2.86 \cdot 10^{7}$ & 0 \\
\hline 4 & $\mathrm{NO}_{2}$ desorption & $\mathrm{NO}_{2}^{*} \rightarrow \mathrm{NO}_{2}(g)+1^{*}$ & $r_{4}=k_{4} \theta_{N O_{2}}$ & $1.32 \cdot 10^{8}$ & 50200 \\
\hline 5 & $\begin{array}{l}\text { Surface } \\
\quad \text { reaction }\end{array}$ & $N O(g)+O^{*} \rightarrow N_{2}^{*}$ & $r_{5}=k_{5} C_{N O} \theta_{O}$ & $6.32 \cdot 10^{7}$ & 55600 \\
\hline 6 & $\begin{array}{l}\text { Surface } \\
\quad \text { reaction }\end{array}$ & $N_{2}^{*} \rightarrow N O(g)+O^{*}$ & $r_{6}=k_{6} \theta_{\mathrm{NO}_{2}}$ & $1.33 \cdot 10^{10}$ & 126000 \\
\hline
\end{tabular}

\subsection{Parallel Model}

The first step is to exploit potential symmetries. In the case of a square channel, it is sufficient to simulate one eighth of the channel as can be seen in Fig. 2. The second step is to perform the sectionalizing itself. This means that the washcoat is divided into $S$ segments based on a uniform angle. Then, each segment is assigned local properties such as washcoat thickness $\left(d_{w s c, s}\right)$, porosity $\left(\varepsilon_{S}\right)$, and external mass transfer coefficient $(k c)$ to allow for variations in local interface concentrations. The washcoat thickness and porosity is based on SEM images as explained below, and the tortuosity is based on intelligent gravimetric analysis (IGA) measurements of the global effective diffusivity. Finally, the tangentially resolved Sherwood number could be retrieved through detailed CFD models; however, as of now, it is set to fixed value while allowing for a local transverse diffusion length scale $d_{S}$ (see eq. 6) to allow for local mass transfer coefficients $k c$. Once the inputs are established, the original 1+1D model is called $S$ times and the outputs - temperature and molar fractionsare weighed together based on the sectionalizing principle (uniform angle). Because each segments' simulations are performed independently in the parallel modelling framework, one important implication applies. Similar to the assumption that there is no mass transfer between axial tanks within the solid phase, the independent computations imply that there cannot be any mass or heat transfer between segments, i.e.

Fig. 2 Left: sectionalizing principle with $\mathrm{S}=3$ segments. Right: parallel, independent function calls to the $1+1 \mathrm{D}$ simulation tool and finally weighing the output

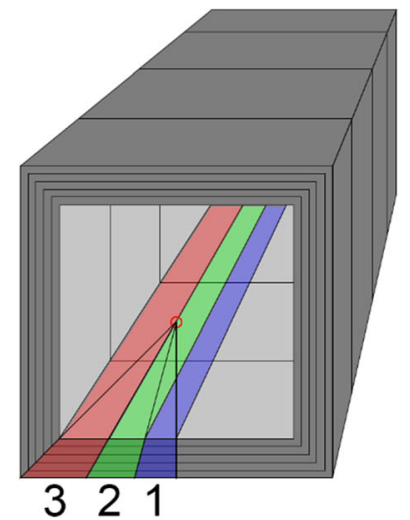

in the tangential direction. This assumption is explored and verified in the results section.

\subsection{Effective Diffusivity Measurements}

There are several available experimental methods for measuring pore diffusivity in washcoated monoliths; various chromatographic methods [28], variants of the classical WickeKallenbach [29] cell as well as different gravimetric methods [30]. Chromatographic methods require very long columns with the sample in pellet form and could therefore be expensive to implement. The Wicke-Kallenbach variant measures diffusivity through two layers of washcoat with the substrate between them. As a consequence, the interaction between the washcoat and the substrate might create dead-end pores which the method cannot account for and as a result this experimental method underestimates effective diffusivity [31]. Gravimetric methods are very expensive and time-consuming, however also accurate since they directly measure the sample uptake rate over time. A Hiden Isochema IGA-001 was used to measure effective diffusivity. The specified measurement error for the chosen operating conditions $\left(0{ }^{\circ} \mathrm{C}, 12 \mathrm{mbar}\right)$ is \pm $0.15 \%$.

In IGA a small sample of washcoated monolith is placed on a balance inside a thermally insulated chamber. The chamber is initially completely evacuated and the sample is heated to desorb any adsorbed species. The chamber is then cooled to a

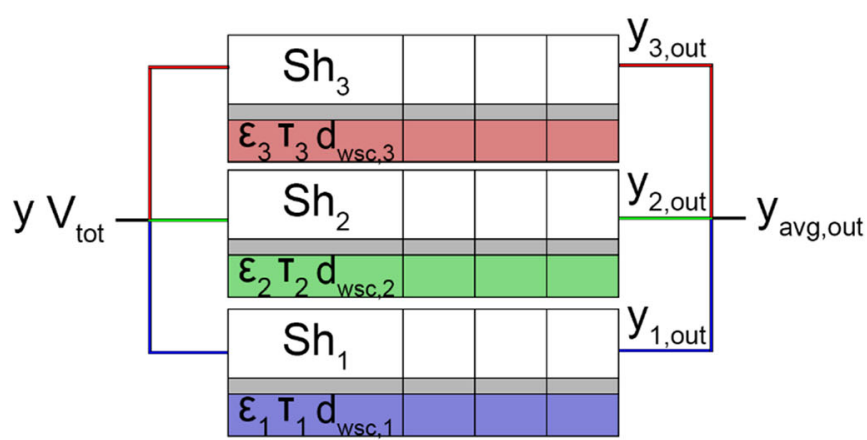


low temperature (usually around $0{ }^{\circ} \mathrm{C}$ ) while maintaining the vacuum. A large slowly diffusing hydrocarbon, e.g. hexane, is kept in a separate liquid reservoir. The evacuated sample chamber is then exposed to stepwise increments of the hydrocarbon vapour pressure which adsorbs onto the washcoat. A pressure regulator keeps the vapour pressure constant (accounting for the adsorbed hydrocarbon) so that the surrounding hydrocarbon concentration is kept constant throughout the experiment. For such a problem, there is a readily available analytical solution [30], from which the effective diffusivity can be extracted:

$\frac{m(t)}{m_{\infty}}=1-e^{-k t}$

where $m(t) / m_{\infty}[-]$ is the ratio of mass adsorbed at time $t[s]$ to mass adsorbed at equilibrium. A different solution is also tested, where the sectionalizing principle is also applied to Eq. 10, which becomes:

$\frac{m(t)}{m_{\infty}}=\sum_{i=1}^{S} \frac{a_{i}}{a_{t o t}}\left(1-e^{-k t}\right)$

Here, the uptake for each segment is weighted together based on the ratio of cross-sectional area for each segment, $a_{i}\left[\mu m^{2}\right]$, to the total cross-sectional area $a_{\text {tot }}\left[\mu \mathrm{m}^{2}\right]$. When Eq. 11 is applied, the uptake rate coefficient is based on the local thickness and porosity for each segment. $k\left[s^{-1}\right]$ is the uptake rate coefficient:

$k=\frac{D_{e f f}}{d_{w s c}^{2}}=\frac{1}{t_{w s c}}$

The uptake rate is the inverse of the characteristic time scale for washcoat diffusion, $t_{w s c}[s][32] . D_{\text {eff }}\left[\mathrm{m}^{2} / \mathrm{s}\right]$ is the effective diffusivity through the washcoat and $d_{w s c}[\mathrm{~m}]$ is the effective diffusion length scale (washcoat thickness). The error from the curve fitting using Eq. (10) is based on comparing the final residual to how the residual changes with a percentual increase in the tortuosity constant. The final residual corresponded to a $6 \%$ change in the tortuosity constant. In order to estimate certain pore model constants from an experimentally observed effective diffusivity, it is necessary to define a reference diffusivity. The chosen reference diffusivity depends on the diffusion regime of the experiment, which in turn depends on the ratio of the pore size to the mean free path of the molecules in the gas phase. It is common to calculate the reference value as a combination of both molecular (when $d_{p}>\lambda$ ) and Knudsen diffusion (when $d_{p}<\lambda$ ), using the Bosanquet equation [18, 29]:

$D_{\text {ref }}=\left(\frac{1}{D_{A B}}+\frac{1}{D_{K n}}\right)^{-1}$ where $D_{r e f}\left[\mathrm{~m}^{2} / \mathrm{s}\right]$ is the reference diffusion coefficient, $D_{A B}\left[\mathrm{~m}^{2} / \mathrm{s}\right]$ is the free molecular diffusivity of species A in $\mathrm{B}$, and $D_{K n}\left[\mathrm{~m}^{2}\right]$ is the Knudsen diffusivity, calculated as:

$D_{K n}=\frac{d_{P}}{3} \sqrt{\frac{8 R T}{\pi M}}$

where $d_{P}[m]$ is the pore diameter for Knudsen diffusion and $M[\mathrm{~g} / \mathrm{mol}]$ is the molecular mass. While some simulations suggest that this formula can be as erroneous as $90 \%$, for $\mathrm{n}$ hexane in $3.4 \mathrm{~nm}$ hexagonal pores with strong adsorption strength, this has yet to be experimentally proven [33]; thus, its potential contribution to the overall error in tuning the tortuosity is disregarded. For IGA, an estimate of the free molecular diffusivity at very low pressure is required. This can be obtained from the Chapman-Enskog method based on solving the Boltzmann equation [34]:

$D_{A B}=\frac{3}{16} \frac{\left(4 \pi k_{B} T / M_{A B}\right)^{1 / 2}}{n \pi \sigma_{A B}^{2} \Omega_{D}}$

where $k_{B}[J / K]$ is Boltzmann's constant, $M_{A B}[\mathrm{~g} / \mathrm{mol}]$ is the reduced molecular mass, $n\left[\mathrm{~mol} / \mathrm{m}^{3}\right]$ is the number density of molecules in the mixture, $\sigma_{A B}^{2}[m]$ is the average collision diameter, and finally $\Omega_{D}[-]$ is the collision integral. To incorporate the dependency on pressure, the number density can be substituted for the ideal gas law. The error of this method compared to experimental data lies on the order of 5 to $10 \%$ according to [34]; however, as the dominating diffusion mechanisms for the current mean pore diameter $\left(d_{P} \approx 11 \mathrm{~nm}\right)$ is Knudsen diffusion, this error is disregarded in this paper.

Finally, to account for the complex structure of the washcoat, Wheeler et al. [35] suggested the random-pore model:

Deff $=\frac{\varepsilon_{P} D_{r e f}}{\tau_{\mathrm{P}}}$

where $\varepsilon_{P}[-]$ is the washcoat porosity and $\tau_{P}[-]$ is the tortuosity. Once the effective diffusivity has been measured using IGA and the pore diffusivity has been calculated using eqs. (12-14), Eq. (16) can be used to calculate the ratio between porosity and tortuosity, i.e. $\varepsilon_{P} / \tau_{P}$. Knowing the porosity for the washcoat (from SEM image analysis), the global tortuosity can be calculated. The tortuosity is assumed to be a property of the meso-structure and should therefore not depend on cracks on the macro-scale; hence, it is kept constant for all segments in the parallel model. The computed diffusivities at IGA conditions $\left(0^{\circ} \mathrm{C}, 12 \mathrm{mbar}\right)$ are presented in the nomenclature. An equivalent error (errors added in quadrature) based on the measurement error and curve fitting was calculated to be $6 \%$, which forms the basis for a sensitivity analysis in the results section. 


\subsection{SEM Analysis}

A $1 \times 1$-in. cylindrical, $400 \mathrm{cpsi}$, DOC — coated with $2.6 \mathrm{~g} \gamma$ alumina/in. ${ }^{3}$ of reactor-was supplied by Johnson Matthey. This sample was analysed used SEM imaging - 16 different segments for calculating porosity and 16 segments for calculating washcoat thickness. The gas/solid interface was tracked in Matlab using pixel luminosity as a guide to distinguish between solid and gas, retrieving the washcoat thickness. ImageJ from National Institutes of Health was in combination with the SEM images used to calculate local (for each segment) and global porosities. It can be argued that SEM image analysis is not a sufficiently accurate way to measure porosity of $\gamma$-alumina since a large part of the pore volume falls below the resolution of a typical electron microscope (resolution for SEM was $1.14 \mu \mathrm{m} / \mathrm{px}$ and $d_{P} \approx 11 \mathrm{~nm}$ ). However, this method gave similar results compared to $\mathrm{Hg}$ porosimetry. Also, it is assumed that (similar to that for constant tortuosity) the microstructure of each segment is unchanged and the changes in porosity originate from the cracks that are clearly visible from the SEM images. Hence, the method is considered adequate to quantify differences in local porosities.

\section{Results and Discussion}

The results are divided into three main sections: results from the local and global washcoat properties, results from simple light-off simulations and lastly verification of the negligible tangential mass transfer. After performing light-off simulations for a varying number of segments $(S \in[1,9])$ it was found that the model showed similar results for $S \geq 3 \mathrm{seg}$ ments; hence, any additional resolution is unnecessary since it requires additional cores to run. Therefore, the results section is only focused on comparing the original model with the parallel model using 3 tangential segments.

\subsection{Global and Local Washcoat Properties}

Figure 3 shows the sectionalizing principle superimposed over a representative SEM image showing an axial cross-section of the washcoated channel. First of all, it can be seen that the washcoat thickness clearly depends on the tangential angle, $\alpha$, where the washcoat is substantially thicker in the corners of the channel. Secondly, a large pit can be seen in the cornerlikely formed during the sintering process. This gives rise to a significant increase in local washcoat diffusivity. Thirdly, it appears as if the micro-structure (excluding the pit) of the washcoat is unchanged with angle $\alpha$-hence, the assumption that the local tortuosity is unchanged seems valid, but also that SEM imaging can be used to estimate local washcoat porosity.

The results from the SEM image analysis is presented in Table 2, where the local and global porosity, tortuosity and

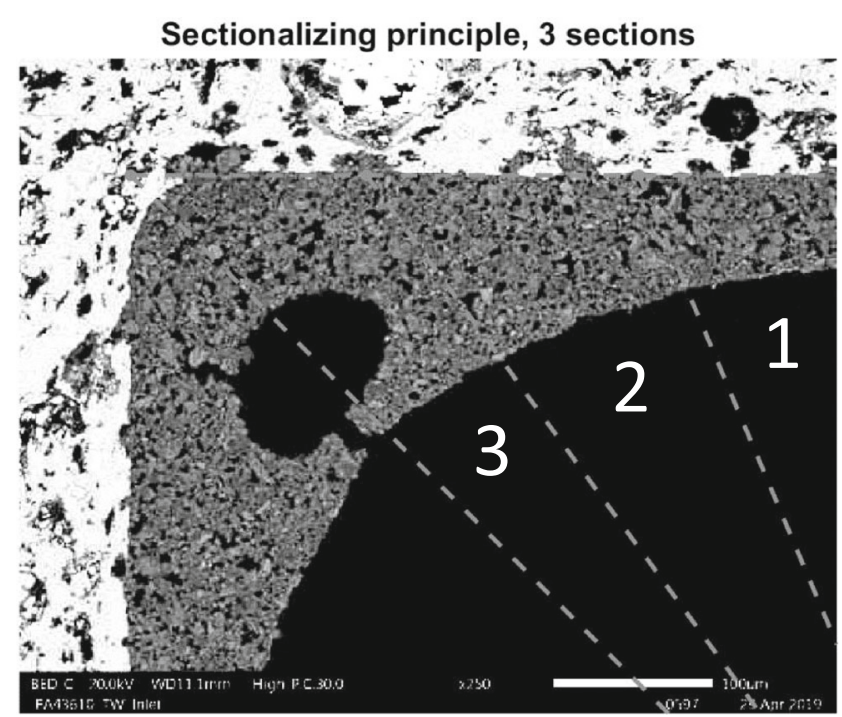

Fig. 3 SEM image showing a representative axial cross-section of the DOC channel. The lighter areas correspond to the monolith, grey areas are washcoat and black is void space. The dotted lines correspond to the superimposed sectionalizing principle for $\mathrm{S}=3$ segments

washcoat thicknesses are shown (the segment with highest identifier corresponds to the corner segment). The global (average) value is simply the area weighed average. These values form the basis for calculating the global and local effective diffusivity. One problem that comes from analysing a 3D material based on axial cross-sections is that the periodicity of the cracks, which affects local porosity, in the axial direction cannot be quantified. It is unlikely that that the pit apparent in Fig. 3 forms one long void throughout the length of the channel-hence, the calculated porosity is, when applied to all tanks in axial direction, likely somewhat overestimated. However, the extreme case of a pit in segment 3 only gives rise to a 2.3 percentage points increase in porosity compared to segment 2, so the absence of these kinds of pits would likely not affect mass transfer that much. It is likely much more important to get the change in washcoat thickness along the channel length correct than to have a correct axially local porosity value. This could easily be accounted for but because of the limited number of received SEM images, taken

Table 2 Global (average) and local washcoat properties. $\tau_{\text {avg }}$ and $\tau_{i}$ corresponds to the tuned tortuosity when using global or local washcoat thickness and porosity, respectively

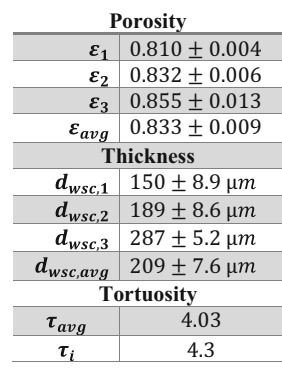


from the inlet region of the catalyst, it is not included. The pit was observed in all corner of the 16 segments. One interesting observation is that the standard deviation for the local washcoat thickness decreases with increased segment identifier (i.e. when moving to the corner). On the contrary, but not so surprisingly, the standard deviation for the local porosity increases with increased segment identifier - where the porosity value in the corner strongly depends on the size of the crack.

The extracted tortuosity from the IGA measurements differed little when comparing Eq. 10 to 11 ; i.e. there is little difference in using local or global values to determine the tortuosity. The simulations are based on $\tau_{\text {avg }}=4.03$, i.e. the tuned tortuosity based on local washcoat thickness and porosity.

\subsection{Light-off Simulations}

For simulations, a temperature ramp between 150 and $500{ }^{\circ} \mathrm{C}$, at $10^{\circ} \mathrm{C} / \mathrm{min}$, was performed with a space velocity of $140^{\prime}$ $000 \mathrm{~h}^{-1}$ (GHSV at NTP). The inlet concentration of NO is $100 \mathrm{ppm}$ in a nitrogen carrier gas flow of $30 \mathrm{~L}_{\mathrm{N}} / \mathrm{min}$ containing $8 \%$ oxygen. The simulated catalyst is a $1 \times 1$-in. cylindrical DOC with $2.6 \mathrm{~g} \gamma$-alumina/in. ${ }^{3}$ reactor, containing $15 \mathrm{~g} \mathrm{Pt} /$ $\mathrm{ft}^{3}$ of reactor. The low reactant concentration and small catalyst ensured an isothermal operation.

The light-off simulations are presented in Fig. 4. Here the normal $1+1 \mathrm{D}$ model is compared to the parallel model. For the parallel model, simulations were performed using either the actual washcoat geometry based on the SEM images (referred to as round) or a theoretical case with a perfectly uniform washcoat (referred to as square). For each case, the simulations are performed with either global or local washcoat properties from Table 2.

It should be noted that there is some conversion even at $150{ }^{\circ} \mathrm{C}$, which experimentally is unlikely. This is likely due to erroneous parameter values in the kinetic model and a quick sensitivity analysis (not presented in this paper) showed that an increase in $E a_{5}$ (i.e. forward surface reaction) indeed decreased the conversion at lower temperature. Furthermore, since there is little sensitivity towards discretization scheme here, the discussion will focus more on the mass transfer limited regime, i.e. $\mathrm{T}>250{ }^{\circ} \mathrm{C}$. The same sensitivity analysis showed that the conversion decreased somewhat in this regime; however, the mutual order of the curves did not change.

There are several important differences to be seen in Fig. 4; firstly, by comparing the 1+1D model (black solid line) with the parallel model using global washcoat properties (red and green curves), conversion is decreased at higher temperatures. This is simply because, regardless of geometry, the parallel model puts emphasis on the thicker washcoat in the cornersi.e. it has a different formulation of what is the effective diffusion length. Where the typical 1+1D model implies that the effective diffusion length is the average washcoat thickness, the parallel model's corner segment is $\sqrt{2}(41 \%)$ times as thick for $\alpha=45^{\circ}$. Therefore, coupled with global washcoat properties, the parallel model increases the diffusion resistance and conversion therefore decreases. There should be a more noticeable difference in conversion by increasing washcoat thickness by $41 \%$; again this likely comes from erroneous parameter values.

Furthermore, by comparing the 1+1D model (black solid line) with the parallel model using local washcoat properties (blue and magenta curves), conversion increases by roughly $13 \%$ for the round geometry. This is a result of an interplay between washcoat thickness and local porosity; segment 1 (thinnest part) has lower porosity than the 1+1D model but is considerably thinner. At the same, time segment 3 is roughly $93 \%$ thicker but has a higher local porosity which increases effective diffusivity - making the catalyst more accessible. This also means that the catalyst has close to $93 \%$ more catalyst mass - though the increased porosity of the corners at the
Fig. 4 Light-off simulations comparing the original $1+1 \mathrm{D}$ model (black), parallel model using global porosity and round geometry (green) and square geometry (red) along with parallel model using local porosity and round geometry (magenta) and square geometry (blue). The error bars (approximately $\pm 2 \%$ ) correspond to a $\pm 6 \%$ change in effective diffusivity for each simulation

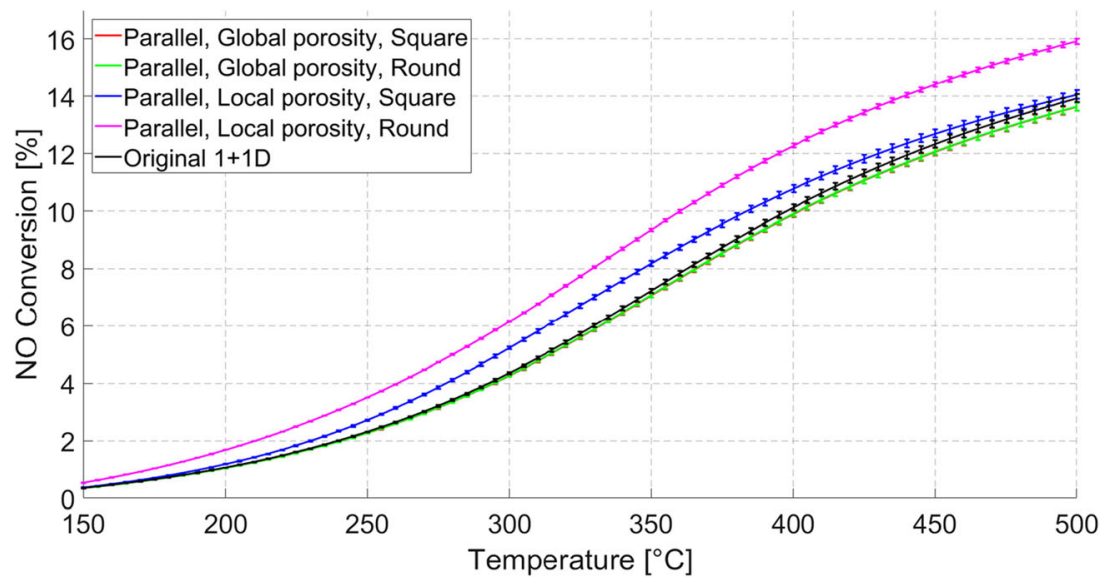


same time lowers the catalyst mass (the local catalyst loading is recalculated from $\mathrm{g} \mathrm{Pt} / \mathrm{ft}^{3}$ of reactor using the channel density and porosity to arrive at $\mathrm{g} \mathrm{Pt} / \mathrm{m}^{2}$ of solid washcoat).

In the case of an assumed square geometry, the local washcoat properties also increase effective diffusivity in the corners-however, since the washcoat is more uniform than in the case of a round geometry, the effects are not as substantial. Additionally, for a square geometry using local porosities, the differences are the largest at intermediate temperatures before likely entering an externally mass transfer limited regime, and the conversion approaches that of the 1+1D model and parallel model with global washcoat properties.

To account for errors in the IGA measurements along with the curve fitting and to investigate the conversion sensitivity towards the effective diffusivity, the tortuosity factor was varied by $\pm 6 \%(\tau=3.79-4.27)$. The results are plotted as error bars in Fig. 4. As expected, with increased tortuosity, thus a lower effective diffusivity, the conversion is decreased-and vice versa. The parallel model with local diffusivity showed the highest sensitivity for a change in the tortuosity constant-which, again, is because of the increased accessibility to the increased $\mathrm{Pt}$ mass in the corners of the channel.

\subsection{Tangential Mass Transfer}

Just like most 1+1D models, assume that the mass transfer in between axial tanks within the washcoat is negligible (because of the dominating radial concentration gradient and mass transfer area), the parallel model assumes that the tangential mass transfer (between segments) is negligible compared to the radial. Both these assumptions can be evaluated by calculating and comparing the potential flux in between tanks:

$J_{D}=-D_{e f f, i} A_{D} \frac{\partial C_{i}}{\partial x_{D}}$

where for any direction $D$ (radial, axial or tangential), $J_{D}[\mathrm{~mol} /$ $s]$ is the flux, $A_{D}\left[\mathrm{~m}^{2}\right]$ is the area between tanks and $\partial C_{i} / \partial x$ ${ }_{i}\left[\mathrm{~mol} / \mathrm{m}^{4}\right]$ is the gradient between tanks. By assuming that the washcoat is isotropic, $D_{\text {eff, } i}$ does not depend on direction if the operation is isothermal. Hence, the difference in potential mass transfer comes from the concentration gradient and the mass transfer area, e.g. the ratio between radial and axial mass transfer is:

$\frac{J_{r a d}}{J_{a x}}=\frac{A_{r a d}}{A_{a x}}\left[\frac{\frac{\partial C_{i}}{\partial x_{r a d}}}{\frac{\partial C_{i}}{\partial x_{a x}}}\right]$

The radial concentration gradient at the inlet, at $500{ }^{\circ} \mathrm{C}$ can be seen in Fig. 5. By comparing the different radial concentration profiles for different axial tanks (i.e. compare lines of same colour at any radial position), it can be seen that there is a substantial concentration gradient in the axial direction. This is due to the fact that the reaction rate is largest in the first axial tanks where reactant concentration is still high. However, since the washcoat is very thin compared to the reactor length, the area for radial diffusion dominates the area for axial diffusion - thus, axial diffusion can be neglected $\left(J_{\text {rad }} / J_{a x} \approx 1.4 \cdot 10^{4}\right)$.

Similarly, by comparing the radial concentration profiles for different segments in the left graph (blue vs green vs red at any radial position), it can be seen that the concentration is virtually the same in all tangential segments. Thus, the tangential mass transfer is assumed negligible $\left(J_{\text {rad }} / J_{\text {tan }} \approx 8.3 \cdot 10^{1}\right)$. It should be mentioned that this is for the extreme case of a round geometry. In more uniform cases, the driving force for tangential mass transfer should be even smaller.

The ratio of radial to tangential mass transfer was also examined at the back of the monolith $\left(J_{\text {rad }} / J_{\text {tan }} \approx 2.4 \cdot 10^{1}\right)$. The tangential mass transfer is still negligible; however, this insight shows that for even longer catalyst samples, there might be a limit, lengthwise, where the model does not represent the true mass transfer within the washcoat. Still, since the reactivity is at its lowest at the back of the catalyst, the change in this ratio should have negligible effects on overall conversion.

\subsection{Simulation Time Aspects}

When it comes to the parallelizability of the parallel model, it retained roughly the same simulation time, which was on the level of real-time. There might be extreme cases where the segments' inputs (e.g. extremely thin or thick washcoats) generate increased stiffness - thus increasing the simulation time compared to the original 1+1D model. Furthermore, if performing a parameter estimation in parallel mode, there will be a need for $\mathrm{S}$ times as many cores if using the parallel model. Lastly, if the parallel model is coupled in a multi-channel model to account for flow maldistribution or heat lossesthis will require additional cores, unless the model is used to create a look up table.

\section{Conclusions}

A novel way to account for local washcoat properties, such as cracks and increased washcoat thickness, was developed. IGA and SEM enabled a locally resolved effective diffusivity as an additional input to the parallel model, though more detailed information about the periodicity of the cracks in the axial direction could be achieved through XRT along with a more accurate porosity value 
Fig. 5 Left: radial concentration profiles for segments 1,2 and 3. Note that segments extend further on the $\mathrm{x}$-axis due its increased thickness. Right: radial concentration profiles for axial tanks 1 and 2

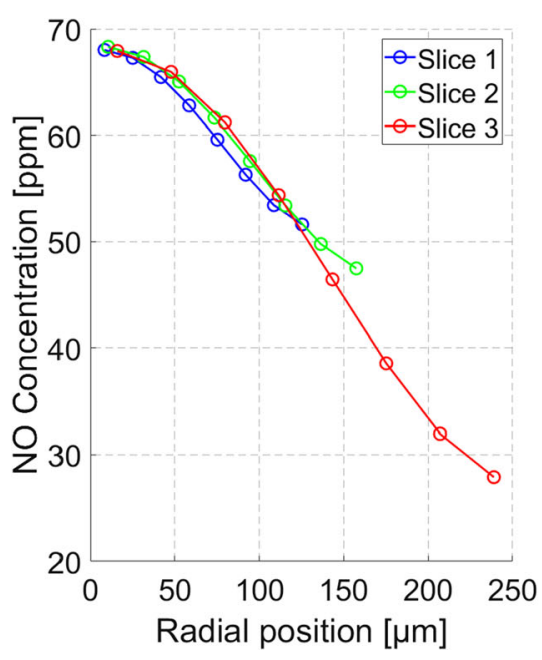

through Hg porosimetry. The parallel model showed model sensitivity at elevated temperatures, especially if using local washcoat properties. The parallel model with global washcoat properties, independent of shape, showed little difference compared to the traditional 1+1D model- thus the slab assumption for 1+1D models should be valid.

It should be stressed that just because the parallel model showed sensitivity in the desired operating region it does not mean that it is more accurate than the original 1+1D model. As of now, both models have identical parameter inputs (kinetic and mass transport). Nonetheless, the visible sensitivity should lead to different mass transfer parameter values in future parameter tuning comparing the parallel and 1+1D model, which could allow for better separation of mass transfer and kinetic effects.

One drawback of the current parallel model is lack of a tangentially resolved Sherwood number. The local external mass transfer with respect to the washcoat perimeter only uses the change in open channel dimension to allow for variations in the external mass transfer coefficient. At least the hydraulic diameter $(d)$ is changed along the perimeter. Since this changes the surface concentrations for each segment, this might affect the validity of the assumed negligible tangential mass transfer. Again, the operation of the DOC never reached the external mass transfer limited region [9]; hence, the importance of the external mass transfer compared to the internal mass transfer should be minor.

One advantage of the parallel model is that it can account for any arbitrary shape and material properties on a 3D level, but with retained simulation time of a 1+1D model, since it is parallelizable over $S$ cores. However, if performing parameter estimation or if the parallel model is coupled in a multichannel model - the parallel model will increase core requirement significantly. Lastly, it should be mentioned that this model could become redundant with improved coating techniques, enabling more uniform washcoat deposition with uniform properties.
Acknowledgements All project members along with the technical support at Johnson Matthey are deeply acknowledged for their help with performing and analysing the experiments. The Swedish Energy Agency (FFI project 42814-1) is acknowledged for financial support.

\section{Compliance with Ethical Standards}

Conflict of Interest The authors declare that they have no competing interests.

Subscripts $i$, species; $j$, reaction number; $k$, tank number; $n$, layer number; $s$, segment number; $a v g$, average or global variable

Nomenclature $A$, area between tanks or layers $\left(\left[\mathrm{m}^{3}\right]\right) ; a_{i}$, cross-sectional area of washcoat segment $\left(\left[\mu \mathrm{m}^{2}\right]\right) ; a_{t o t}$, total cross-sectional area of washcoat $\left(\left[\mu^{2}\right]\right) ; c$, concentration $\left(\left[\mathrm{mol} / \mathrm{m}^{3}\right]\right) ; d$, open channel dimension ([m]); $D$, free molecular diffusivity $\left(\left[\mathrm{m}^{2} / \mathrm{s}\right]\right) ; D_{A B}$, free molecular diffusivity of component $A$ in $B$, typically $175 \cdot 10^{-6}\left(\left[\mathrm{~m}^{2} / \mathrm{s}\right]\right) ; D_{K n}$, Knudsen diffusivity, typically $3.01 \cdot 10^{-9}\left(\left[\mathrm{~m}^{2} / \mathrm{s}\right]\right)$; Deff, effective diffusivity, typically $5.8 \cdot 10^{-10}\left(\left[\mathrm{~m}^{2} / \mathrm{s}\right]\right) ; d_{P}$, pore diameter, typically $11 \cdot 10^{-9}([\mathrm{~m}]) ; D_{\text {ref }}$, reference diffusivity, typically $3.01 \cdot 10^{-9}\left(\left[\mathrm{~m}^{2} / \mathrm{s}\right]\right) ; d_{w s c}$, washcoat thickness $([\mathrm{m}]) ; E a_{j}$, activation energy $([\mathrm{J} / \mathrm{mol}]) ; F_{t o t}$, total molar flow rate in the gas phase $([\mathrm{mol} / \mathrm{s}]) ; G z$, Graetz number $([-]) ; J_{D}$, molecular flux $\left(\left[\frac{\mathrm{mol}}{\mathrm{m}^{2} s}\right]\right) ; k$, uptake rate coefficient $\left(\left[\mathrm{s}^{-1}\right]\right) ; k_{B}$, Boltzmann's constant $([J / K]) ; k c$, external mass transfer coefficient $([\mathrm{m} / \mathrm{s}]) ; k$, reaction rate constant $\left(\left[\mathrm{m}^{3} / \mathrm{s}\right]\right) ; M$, molecular mass $([\mathrm{g} / \mathrm{mol}]) ; M_{A B}$, reduced molecular mass of species $A$ and $B([\mathrm{~g} / \mathrm{mol}]) ; m$, mass of catalyst $([\mathrm{kg}]) ; \frac{\mathrm{m}(\mathrm{t})}{m_{\infty}}$, ratio of mass adsorbed at time $t$ to mass adsorbed at equilibrium $([-]) ; n$, number density $\left(\left[\mathrm{mol}_{3} \mathrm{l} / \mathrm{m}^{3}\right]\right) ; N u_{\infty, T}$, asymptotic Nusselt number ([-]); $R$, gas constant ( $\left.\left(\frac{\mathrm{Pa} \mathrm{m}^{3}}{\mathrm{~mol} \mathrm{~K}}\right)\right) ; r$, reaction rate $([\mathrm{mol} / \mathrm{s}]) ; \mathrm{Sh}$, asymptotic Sherwood number $([-]) ; t$, time $([s]) ; T$, temperature $([K]) ; T_{r e f}$, reference temperature for preexponential factor $([K]) ; V$, volume of tank $\left(\left[\mathrm{m}^{3}\right]\right) ; v$, stoichiometric coefficient $([-]) ; y$, gas phase molar fractions $([-]) ; z^{*}$, dimensionless axial coordinate (inverse Graetz number) $([-])$

Greek Symbols $\Gamma_{i, k, n}$, mass transfer coefficient for species $i$ in tank $k$ in layer $n\left(\left[\mathrm{~m}^{3} / s\right]\right) ; \Delta x_{n}$, radial thickness of layer $n([\mathrm{~m}]) ; \varepsilon$, washcoat porosity for $1+1 \mathrm{D}$ model $([-]) ; \varepsilon_{P}$, washcoat porosity in diffusivity calculations $([-]) ; \theta_{i}$, fractional coverage of species $i([-]) ; \sigma_{A B}^{2}$, average collision diameter $([m]) ; \tau_{P}$, tortuosity $([-]) ; \Omega_{D}$, collision integral $([-])$

Open Access This article is licensed under a Creative Commons Attribution 4.0 International License, which permits use, sharing, adaptation, distribution and reproduction in any medium or format, as long as 
you give appropriate credit to the original author(s) and the source, provide a link to the Creative Commons licence, and indicate if changes were made. The images or other third party material in this article are included in the article's Creative Commons licence, unless indicated otherwise in a credit line to the material. If material is not included in the article's Creative Commons licence and your intended use is not permitted by statutory regulation or exceeds the permitted use, you will need to obtain permission directly from the copyright holder. To view a copy of this licence, visit http://creativecommons.org/licenses/by/4.0/.

\section{References}

1. Russell, A., Epling, W.S.: Diesel oxidation catalysts. Catal. Rev. 53(4), 337-423 (2011)

2. Önsan ZI, Avci AK. Monolith reactors. Multiphase catalytic reactors - theory, design, manufacturing, and applications: John Wiley \& Sons; 2016

3. Chen, J., Yang, H., Wang, N., Ring, Z., Dabros, T.: Mathematical modeling of monolith catalysts and reactors for gas phase reactions. Appl. Catal. A Gen. 345(1), 1-11 (2008)

4. Roy, S., Bauer, T., Al-Dahhan, M., Lehner, P., Turek, T.: Monoliths as multiphase reactors: a review. AICHE J. 50(11), 2918-2938 (2004)

5. Depcik, C., Srinivasan, A.: One + one-dimensional modeling of monolithic catalytic converters. Chem. Eng. Technol. 34(12), 1949-1965 (2011)

6. Güthenke A, Chatterjee D, Weibel M, Krutzsch B, Kočí P, Marek $\mathrm{M}$, et al. Current status of modeling lean exhaust gas aftertreatment catalysts. In: Marin GB, editor. Advances in Chemical Engineering. 33: Academic Press; 2007. p. 103-283

7. Groppi, G., Ibashi, W., Valentini, M., Forzatti, P.: Hightemperature combustion of $\mathrm{CH} 4$ over $\mathrm{PdO} / \mathrm{Al} 2 \mathrm{O} 3$ : kinetic measurements in a structured annular reactor. Chem. Eng. Sci. 56(3), 831-839 (2001)

8. Walter, S., Malmberg, S., Schmidt, B., Liauw, M.A.: Mass transfer limitations in microchannel reactors. Catal. Today. 110(1), 15-25 (2005)

9. Walander, M., Sjöblom, J., Creaser, D., Lundberg, B., Tamm, S., Edvardsson, J.: Efficient experimental approach to evaluate mass transfer limitations for monolithic DOCs. Top. Catal. 62(1), 391396 (2019)

10. Hayes, R.E., Kolaczkowski, S.T.: Mass and heat transfer effects in catalytic monolith reactors. Chem. Eng. Sci. 49(21), 3587-3599 (1994)

11. Hayes, R.E., Liu, B., Votsmeier, M.: Calculating effectiveness factors in non-uniform washcoat shapes. Chem. Eng. Sci. 60(7), 2037$2050(2005)$

12. Hayes, R.E., Liu, B., Moxom, R., Votsmeier, M.: The effect of washcoat geometry on mass transfer in monolith reactors. Chem. Eng. Sci. 59(15), 3169-3181 (2004)

13. Mladenov, N., Koop, J., Tischer, S., Deutschmann, O.: Modeling of transport and chemistry in channel flows of automotive catalytic converters. Chem. Eng. Sci. 65(2), 812-826 (2010)

14. Papadias, D., Edsberg, L., Björnbom, P.: Simplified method of effectiveness factor calculations for irregular geometries of washcoats: a general case in a 3D concentration field. Catal. Today. 60(1), 11-20 (2000)

15. Gunn, D.J.: Diffusion and chemical reaction in catalysis and absorption. Chem. Eng. Sci. 22(11), 1439-1455 (1967)

16. Papadias, D., Edsberg, L., Björnbom, P.: Simplified method for effectiveness factor calculations in irregular geometries of washcoats. Chem. Eng. Sci. 55(8), 1447-1459 (2000)
17. Novák, V., Kočí, P., Gregor, T., Choi, J.-S., Štěpánek, F., Marek, M.: Effect of cavities and cracks on diffusivity in coated catalyst layer. Catal. Today. 216, 142-149 (2013)

18. Lundberg, B., Sjöblom, J., Johansson, Å., Westerberg, B., Creaser, D.: DOC modeling combining kinetics and mass transfer using inert washcoat layers. Appl. Catal. B Environ. 191, 116-129 (2016)

19. Lundberg, B., Sjoblom, J., Johansson, Å., Westerberg, B., Creaser, D.: Parameter estimation of a DOC from engine rig experiments with a discretized catalyst washcoat model. SAE Int. J. Engines. 7(2), 1093-1112 (2014)

20. Kryl, D., Kočí, P., Kubíček, M., Marek, M., Maunula, T., Härkönen, M.: Catalytic converters for automobile diesel engines with adsorption of hydrocarbons on zeolites. Ind. Eng. Chem. Res. 44(25), 9524-9534 (2005)

21. Kočí, P., Marek, M., Kubíček, M., Maunula, T., Härkönen, M.: Modelling of catalytic monolith converters with low- and hightemperature NOx storage compounds and differentiated washcoat. Chem. Eng. J. 97(2), 131-139 (2004)

22. Chatterjee D, Burkhardt T, Bandl-Konrad B, Braun T, Tronconi E, Nova I, et al. Numerical simulation of ammonia SCR-catalytic converters: model development and application. SAE International; 2005

23. Bhattacharya, M., Harold, M.P., Balakotaiah, V.: Shape normalization for catalytic monoliths. Chem. Eng. Sci. 59(18), 3737-3766 (2004)

24. Joshi, S.Y., Harold, M.P., Balakotaiah, V.: Low-dimensional models for real time simulations of catalytic monoliths. AICHE J. 55(7), 1771-1783 (2009)

25. Dadi, R.K., Luss, D., Balakotaiah, V.: Dynamic hysteresis in monolith reactors and hysteresis effects during co-oxidation of $\mathrm{CO}$ and C2H6. Chem. Eng. J. 297, 325-340 (2016)

26. Tronconi, E., Forzatti, P.: Adequacy of lumped parameter models for SCR reactors with monolith structure. AICHE J. 38(2), 201-210 (1992)

27. Pritchard, D.J., Bacon, D.W.: Prospects for reducing correlations among parameter estimates in kinetic models. Chem. Eng. Sci. 33(11), 1539-1543 (1978)

28. Starý, T., Šolcová, O., Schneider, P., Marek, M.: Effective diffusivities and pore-transport characteristics of washcoated ceramic monolith for automotive catalytic converter. Chem. Eng. Sci. 61(18), 5934-5943 (2006)

29. Hayes, R.E., Kolaczkowskib, S.T., Li, P.K.C., Awdry, S.: Evaluating the effective diffusivity of methane in the washcoat of a honeycomb monolith. Appl. Catal. B Environ. 25(2), 93-104 (2000)

30. Ruthven, D.M.: Diffusion in type a zeolites: new insights from old data. Microporous Mesoporous Mater. 162, 69-79 (2012)

31. Guangsuo, Y., Jianguo, Y., Zunhong, Y.: The measurement of effective diffusivity for sulfur-tolerant methanation catalyst. Chem. Eng. J. 78(2), 141-146 (2000)

32. Metkar, P.S., Balakotaiah, V., Harold, M.P.: Experimental study of mass transfer limitations in Fe- and cu-zeolite-based NH3-SCR monolithic catalysts. Chem. Eng. Sci. 66(21), 5192-5203 (2011)

33. Krishna, R.: Investigating the validity of the Knudsen diffusivity prescription for Mesoporous and macroporous materials. Ind. Eng. Chem. Res. 55(16), 4749-4759 (2016)

34. Bruce, E.P., John, M.P., John, P.O.C.: Properties of Gases and Liquids, 4th and 5th edn. McGraw-Hill Education, New York (2001)

35. Wheeler A. Catalysis. In: Emmett PH, editor. 2. New York: Reinhold Publishing Corporation; 1955. p. 105

Publisher's Note Springer Nature remains neutral with regard to jurisdictional claims in published maps and institutional affiliations. 